\title{
Comentario No1 "Seguel con Fisco de Chile" La Responsabilidad del Estado-Administración: ¿Una "Perinola Jurisprudencial"?
}

\author{
Cristián Román Cordero \\ Instructor de Derecho Administrativo \\ Universidad de Chile
}

\section{Ideas generales}

En reiteradas oportunidades he planteado mi disconformidad con el actual estado de cosas en materia de responsabilidad del Estado-Administrador ${ }^{1}$. En síntesis, he cuestionado la escasa regulación legal de esta materia, a pesar de la trascendental importancia que ella tiene en la conformación del Estado de Derecho. Defecto del cual naturalmente se siguen otros dos: la extrema polarización doctrinal, que afecta no sólo al alcance conceptual de los presupuestos que la hacen procedente sino que su enumeración y con ello las características generales del sistema (v.gr., si es objetivo o subjetivo, con o sin falta de servicio, etcétera), y el ilimitado radio de interpretación del que indebidamente dispone el juez en relación a este instituto, que le permite fallar y fundar satisfactoriamente, frente a casos cuyas circunstancias fácticas son idénticas o análogas ${ }^{2}$, no sólo en forma distinta sino que, también, contradictoria, todo lo cual nos revela que, en la práctica, el juez es el "amo y seńor" de esta materia, y no el legislador, como debiera serlo, conforme lo ordena la Constitución ${ }^{3}$.

Tal estado de cosas genera, además, problemas de singular gravedad, que el Legislador debería ponderar a efectos de determinar si ya es hora de legislar, con carácter general, sobre esta materia. Entre tales problemas merecen destacarse al menos los siguientes:

\footnotetext{
Sobre este particular, véase: ROMÁN CORDERO, Cristian, "La Responsabilidad Patrimonial de la Administración del Estado y su Necesaria Modelación Legal en Base a la Enumeración y Delimitación Conceptual de sus Presupuestos", Revista de Derecho Público, Chile, N 66, 2004, p. 405 y ss. ROMAN CORDERO, Cristian, "Responsabilidad Patrimonial de la Administración del Estado: Bases para la Construcción de un Nuevo Sistema", Actas de las XXXIV Jornadas de Derecho Público, Santiago, Editorial Lexis Nexis, 2005, p. 509 y ss. ROMAN CORDERO, Cristian, Responsabilidad patrimonial de la Administración del Estado en Chile, en PANTOJA BAUZA, Rolando (coord.), Derecho Administrativo Chileno, Editorial Porrúa, México DF, 2007, p. 734 y ss. La misma crítica en relación al sistema español, puede apreciarse en: SANTAMARÍA PASTOR, Juan Alfonso. Prólogo al libro de DE AHUMADA RAMOS, Javier, La responsabilidad patrimonial de las Administraciones públicas. Elementos estructurales: lesión de derechos y nexo causal entre la lesión y el funcionamiento de los servicios públicos, Editorial Aranzadi, Navarra 2000, p. 21. REBOLLO, Luis Martín, Ayer y hoy de la responsabilidad patrimonial de la Administración: un balance y tres reflexiones, Revista de Administración Público No 150, septiembre-diciembre 1999, p. 328 y ss. MIR PUIGPELAT, Oriol, La responsabilidad patrimonial de la Administración. Hacia un nuevo sistema, Editorial Civitas, Madrid 2002, p. 292 y ss.

Incisos finales de los artículos $6^{\circ}$ y $7^{\circ}$ de la Constitución Política.
} 
crea una manifiesta inseguridad jurídica (en cuanto a los resultados de una acción de responsabilidad en contra del Estado-Administrador), establece diferencias entre iguales, contraviniendo así el mandato constitucional contenido en el artículo 19 No $2 \mathrm{y}$, finalmente, impide que en esta materia participen, como puede observarse en el Derecho Comparado, compañías de seguro, las que, al no tener ni aun mediana certeza en cuanto a los riesgos asumidos, se abstienen de ello ${ }^{4}$.

\section{Aspectos relevantes del fallo que serán objeto de comentario}

Pues bien, la sentencia que comento ${ }^{5}$ se encardina precisamente dentro de esta incontrolada e imprevisible jurisprudencia ${ }^{6}$, cuestión que evidencia en dos órdenes de materias: (a) restableciendo el carácter general de la falta de servicio e interrumpiendo así la jurisprudencia que se había sentado en cuanto a que sólo los usuarios de servicios públicos podían reclamar la ocurrencia de falta de servicio, y (b) creando una nueva regla de responsabilidad -factor de atribución- en relación a aquella que afecta al Estado por las actuaciones lesivas de las FFAA: la falta de servicio.

\section{Primer aspecto a comentar: la falta de servicio como factor de atribución exclusivo de los usuarios del servicio}

La Corte Suprema, hace más o menos un lustro, precisó el alcance del factor de atribución falta de servicio: ella sólo podía ser alegada por quienes tuvieran la calidad de usuarios del servicio. Esta tesis debutó trágica e injustamente, en mi opinión, en "Arévalo Bascunán, Paula con Fisco de Chile", caso en el que, en Tocopilla, un gendarme, que seguía un reo evadido por la calle, percutó algunos disparos en su contra, uno de los cuales impactó en una transeúnte, quedando parapléjica. La Corte Suprema entendió que ella no era usuaria del servicio y, por ello, no podía argüir para sí la existencia de falta de servicio, razón por la cual, finalmente, no fue indemnizada. Ciertamente, es un fallo criticable, no sólo por su injusto resultado sino también porque no es posible advertir fundamento alguno en nuestro ordenamiento jurídico para efectuar tal limitación, ni siquiera en el subsistema en el que los alcances de la falta de servicio se encuentran mejor desarrollados como acontece en los artículos 38 y siguientes de la Ley No 19.966 -en relación a la responsabilidad de los órganos de la Administración del Estado en materia sanitaria.

4 Sobre este punto véase: ARQUILLO COLET, Begoña, Seguro y responsabilidad patrimonial de la Administración. Los problemas de aseguramiento de la responsabilidad civil de la administraciones públicas y sus soluciones jurídicas, Tesis doctoral, Universidad de Barcelona, Barcelona 2006.

5 Sentencia de la Corte Suprema "Seguel con Fisco de Chile", Rol No 371-2008, de 30 de julio de 2009.

6 Sobre esta realidad puede verse: CORDERO VEGA, Luis, Bases de comprensión para la jurisprudencia judicial de responsabilidad extracontractual de la administración, Revista de Derecho Público, No 66, 2004, p. 371 y ss. 
Pues bien, la sentencia en comento innova nuevamente y lo hace en términos de reconocer a la falta de servicio un carácter amplio y no restringido, pues no obstante haber sido argüido por la defensa fiscal la tesis antes señalada, la Corte expresamente resolvió que "la noción de falta de servicio debe ser analizada independientemente y no en relación a los posibles usuarios del servicio público, pudiendo comprometerse la responsabilidad del Estado por falta de servicio que cause daño a terceras personas que no sean usuarias del órgano estatal que la cometió", posición que comparto plenamente y de la que espero la Corte no vuelva a apartarse.

\section{Segundo aspecto a comentar: la falta de servicio como un factor de atribución conforme al cual el Estado responde por las actuaciones lesivas de las FFAA.}

Luego la Corte, en el fallo en comento, analiza la particular situación de las FFAA en relación a la responsabilidad patrimonial del Estado, la cual puede resumirse de la siguiente manera: las FFAA son órganos de la Administración del Estado, conforme previene el artículo $1^{\circ}$ de la Ley No 18.575, Orgánica Constitucional de Bases Generales de la Administración del Estado (en adelante, LOCBGAE), mas a ellas, por mandato de su artículo 21 inciso $2^{\circ}$, no le es aplicable su Título II, en el cual se encuentra el artículo 42, que dispone: "Los órganos de la Administración serán responsables del daño que causen por falta de servicio". ¿Qué norma rige, por tanto, en relación a tales órganos en esta materia? La respuesta nos la otorga el referido artículo 21 inciso $2^{\mathrm{o}}$ : lo que disponga su respectiva ley orgánica constitucional (de FFAA), mas ésta nada dice sobre el particular.

Atendido lo señalado en el párrafo anterior, el fallo razona en orden a determinar cuál es la regla de responsabilidad que debe ser aplicada al Estado respecto de los dańos ocasionados a particulares por las FFAA. En efecto, si bien la jurisprudencia había sido bastante vacilante -como parece ser la constante en este orden de materias-, ya que había resuelto este problema, por ejemplo, aplicando el artículo 38 inciso $2^{\circ}$ de la Constitución -como sistema objetivo-, el artículo $4^{\circ}$ de la LOCBGAE -como sistema objetivo-, el artículo 2320 del Código Civil -responsabilidad por el hecho ajeno-, desarrollando la figura de una infracción o inactividad sin identificarla como falta de servicio, etcétera, el fallo en comento innova y recoge plenamente la solución planteada por el profesor Pedro Pierry Arrau: aplicar el artículo 2314 del Código Civil en términos tales que permitan entender incorporados en la expresión "culpa" a la "falta de servicio", de tal suerte que se complete y uniforme el sistema de responsabilidad patrimonial de la Administración del Estado?.

Señala el profesor antes citado: "En nuestra opinión se debe lograr la aplicación, en definitiva, de un solo sistema de responsabilidad para toda la Administración del Estado, pero sin desconocer que el artículo 44 no se puede aplicar a las instituciones excluidas. Ello puede hacerse aplicando la institución de la falta de servicio, pero no a partir del artículo 44, o del artículo 38 de la Constitución, como lo hizo el juez de primera instancia en el 
La solución seguida por el fallo nos genera serias dudas en cuatro órdenes de materias. A saber: (1) la aplicación supletoria de las normas del Código Civil en la resolución de problemas de Derecho Administrativo, en la especie la responsabilidad patrimonial de la Administración del Estado, (2) la interpretación in extremis que se hace del artículo 2314, a tal punto de inferir que en la expresión culpa se encuentra contenido el factor de atribución propio de Derecho Público: falta de servicio, (3) la relevancia que el fallo otorga a la necesidad de uniformar el sistema de responsabilidad patrimonial de la Administración del Estado, y (4) la contravención evidente que dicha interpretación importa del ordenamiento jurídico público, en cuanto a que a la responsabilidad patrimonial del Estado por actuaciones de las FFAA no se le aplica el factor de atribución falta de servicio.

Primer punto. El fallo supone la aplicación supletoria de las normas del Código Civil en la resolución de problemas propios de Derecho Administrativo, en la especie de responsabilidad patrimonial de la Administración del Estado.

En mi opinión, la responsabilidad patrimonial del Estado-Administrador es autónoma de la responsabilidad civil extracontractual. En síntesis, fundo aquello en las sustanciales diferencias que se observan entre ambos sistemas de responsabilidad en lo que concierne a los sujetos, la incidencia de facultades o potestades públicas, los deberes prestaciones del Estado -de lo que se sigue la trascendental importancia que en el sistema de responsabilidad que le es propio adquiere la inactividad administrativa-, etcétera ${ }^{8}$.

Así las cosas, a mi juicio, las lagunas que se aprecian en el sistema de responsabilidad patrimonial del Estado-Administrador deben ser integradas, primeramente, con normas del propio sistema (subsistemas) o con normas de Derecho Público en general, y sólo de forma excepcional, en el caso que en este último no exista norma que satisfactoriamente sirva para ese cometido, y por tratarse de materias de naturaleza patrimonial, cabe aplicar las normas del Código Civil, primeramente, las generales no insertas en el Título relativo a los delitos y cuasidelitos (artículo 2314 y siguientes del Código Civil) y, finalmente, cuando ello no es posible, aquéllas insertas en este último.

En todo caso, estimo que lo anteriormente dicho tiene, excepcionalmente, menor vigor cuando la laguna se verifica en relación al factor de atribución, esto es, el fundamento de la obligación indemnizatoria que atribuye jurídicamente el daño al Estado, tal como sucede en la especie, ya que preferentemente debe ser integrada, por ser este tópico consustancial al Derecho Público, con normas de esta naturaleza.

Finalmente, cabe señalar que si bien el Derecho Administrativo surge tomando como

caso de homicidio de los profesores Nattino, Parada y Guerrero, en el Considerando 230 de la sentencia, posteriormente eliminado por el fallo de alzada, sino que a partir del artículo 2314 del Código Civil, al que habría que volver como el derecho común en materia de responsabilidad extracontractual” PIERRY ARRAU, Pedro, Responsabilidad extracontractual por falta de servicio, en VVAA, Responsabilidad Extracontractual del Estado, Editorial Metropolitana, Santiago 2009, p. 57-58.

8 Véase: ROMÁN CORDERO, Cristian, Inactividad administrativa y responsabilidad del Estado, Revista de Derecho Público, No 67, p. 402 y ss. 
esquema al Derecho Civil ${ }^{9}$, que indudablemente durante el Siglo XIX constituyó el Derecho Común -incluso se ha señalado por Jean Carbonnier que el Código Civil en dicho siglo habría sido, en la práctica, la Constitución de muchos países-, hoy es innegable que el Derecho Administrativo detenta un cuerpo sólido de principios y reglas, insertas en el sistema de Derecho Público, que difieren sustancialmente de aquellos que informan el Privado, razón por la cual cada vez es más dudoso recurrir a éste último como Derecho supletorio del Derecho Administrativo, tal como lo ha hecho el fallo en comento, por más que así lo pretenda el artículo $4^{\circ}$ del Código Civil ${ }^{10}$.

Segundo punto. Ahora bien, la Corte al aplicar el artículo 2314 en el fallo en comento, lo hace en el entendido que en la expresión culpa que emplea debe entenderse contenido el factor de atribución propio del Derecho Público: la falta de servicio.

A mi juicio, puede admitirse que la expresión culpa puede ser entendida en términos desvinculados de aspectos volitivos que evoca la idea de "pecado jurídico" y en ese sentido más cercana a la idea de infracción de un deber de cuidado ${ }^{11}$, pudiendo así aplicarse dicho precepto a las personas jurídicas en forma directa y despersonalizada, como culpa anónima o difusa, pero otra cosa muy distinta es entender que en dicho precepto legal -art. 2314 del Código Civil- está contenido el factor de atribución falta de servicio.

A mi juicio ello, no es admisible sostener esto último, no sólo por el carácter público de la falta de servicio, que impediría sostener que ella se encuentre recogida en normas de Derecho Privado, sino, además, por la singular flexibilidad que la caracteriza, y que se explica por la necesidad que tiene, a diferencia de los factores de atribución del Derecho Privado, de conciliar intereses diametralmente distintos, flexibilidad de la que se sigue que, para que ella se verifique, no basta, por regla general, la ocurrencia de infracción, inactividad o ilegalidad sino que, además, debe ser susceptible reproche jurídico, para cuya determinación deberán considerarse variados aspectos, tales como deberes normativos, previsibilidad del dańo, derechos afectados, medios personales y presupuestarios del servicio, etcétera, algunos de los cuales se encuentran recogidos en la responsabilidad civil extracontractual, en tanto que otros que le son completamente ajenos.

Si el fallo pretendía al aplicar el artículo 2314 del Código Civil tener un fundamento positivo para sostener que la responsabilidad podía producirse con la infracción de un deber de actuar -lo que constituye una hipótesis de inactividad administrativa y que no es necesariamente falta de servicio, conforme se ha explicado-, pudo haber

9 MARTIN RETORTILLO BAQUER, Sebastián, El Derecho Civil en la génesis del Derecho Administrativo y de sus instituciones, Instituto García Oviedo, Sevilla 1960. PLESSIX, Benoît, L'utilisation du droit civil dans l'elaboration du droit administratif, Editions Panthéon-Assas (Paris II), Paris, 2003.

10 En este sentido véase: VERGARA BLANCO, Alejandro. "Derecho Administrativo y supuesta supletoriedad del Código Civil”, en ARANCIBIA MATTAR, Jaime y MARTINEZ ESTAY, José Ignacio (coord.). La Primacía de la Persona. 1era edición, Santiago, Editorial Legal Publishing, 2009, p. 259 y ss.

11 Véase: BARROS BOURIE, Enrique, Tratado de Responsabilidad Extracontractual, Editorial Jurídica de Chile, Santiago 2007, p. 94 y ss. 
prescindido de él y haber aplicado el artículo $4^{\circ}$ de la LOCBGAE, aplicable en la especie, obteniendo idéntico resultado.

En efecto, de dicho precepto legal se infiere que la responsabilidad del Estado-Administrador se compromete con la ocurrencia de al menos tres presupuestos: actuación administrativa, dańo y relación de causalidad. Teniendo presente que la actuación puede verificarse de dos maneras: actuación propiamente tal o inactividad -u omisión- y que esta última siempre es la infracción de un deber ${ }^{12}$, la Corte podría, en base a este precepto legal, haber constatado tal infracción y, a su vez, la inactividad administrativa -que para estos efectos hace las veces de factor de atribución-, llegando a idéntico resultado, eso sí que, a diferencia de la solución que el fallo plantea, sin recurrir a normas foráneas del sistema de responsabilidad patrimonial de la Administración del Estado.

Tercer punto. El fallo en comento para fundar su decisión en cuanto a aplicar el factor de atribución falta de servicio a las FFAA, agrega que lo hace para uniformar el sistema de responsabilidad patrimonial de la Administración del Estado, o sea, entiende que es un imperativo que dicha responsabilidad, ya sea en relación a todos los órganos del Estado o en relación a todas las actuaciones que desarrolla, se conformen a un mismo sistema: por falta de servicio.

¿Es aquello necesario, tal como sostiene el fallo en comento?

A mi juicio, no es ni puede ser así. Ello porque el Estado realiza muchísimas clases de actividades, disímiles entre sí, lo que impide, a no ser que se pretenda obviar aquello, aplicar siempre un mismo sistema de responsabilidad. En este sentido no puede olvidarse que el mismo arrêt Blancô del Tribunal de Conflictos de Francia, señero en esta materia, claramente sostuvo que la responsabilidad que puede afectar al Estado por el hecho de sus agentes "no es general ni absoluta"13.

A mayor abundamiento, no hay norma en la Constitución, que de forma expresa exija un régimen uniforme de responsabilidad patrimonial de la Administración del Estado, sino más bien al contrario, confiere al legislador gran libertad para su definición, como la misma Corte Suprema en otros fallos expresamente lo ha entendido. Así las cosas, nada obsta para que el legislador establezca subsistemas de responsabilidad respecto de ciertos órganos o ciertas actuaciones, ya sea en relación al factor de atribución o a aspectos accesorios -daño, concausalidad, riesgos del desarrollo, falta personal, etcétera-, en términos distintos e incluso opuestos al régimen consultado en el artículo 42 de la LOCBGAE, tal como acontece, por ejemplo, con el subsistema de responsabilidad de los órganos de la Administración en materia sanitaria (artículos 38 y siguientes de la Ley No 19.966 (AUGE) $)^{14}$; el subsistema de responsabilidad de las municipalidades:

12 Véase: GÓMEZ PUENTE, Marco, La inactividad de la Administración, Editorial Aranzadi, Pamplona, 1997.

13 Véase: PANTALEÓN PRIETO, Fernando, Los anteojos del civilista: hacia una revisión del régimen de responsabilidad patrimonial de las Administraciones Públicas, Revista de Derecho del Consejo de Defensa del Estado, No 2, año 1, diciembre 2000, p. 92 y ss. MIR PUIGPELAT, Oriol, Op. Cit., p. 309 y ss.

14 Sus lineamientos generales son los que observo a continuación: (a).- rige los daños consecuentes a la actuación sanitaria de la Administración del Estado; (b) el factor de atribución de este subsistema es la "falta de servicio"; (c) circunscribe la "falta personal" a la imprudencia temeraria y al dolo del funcionario en el ejercicio de sus 
principalmente por falta de servicio (artículo 142 de Ley No 18.695, Orgánica Constitucional de Municipalidades) y por reclamo de ilegalidad acogido (artículo 141 letra i de la misma ley); subsistema de responsabilidad del Fisco y municipalidades, en su caso, por daños consecuentes del mal estado, falta o deficiente señalización de las vías públicas (artículo 174 inciso $5^{\circ}$ de la Ley No 18.290, del Tránsito); etcétera.

En consecuencia, la uniformidad del sistema, a la que se refiere el fallo, no es ni una realidad ni una necesidad y, en consecuencia, no puede ser empleado satisfactoriamente como argumento a favor de una tesis vis expansiva de la falta de servicio, incluso si ésta se ampara en el Código Civil, pretendidamente supletorio para estos efectos.

Cuarto punto. Finalmente cabe observar que el fallo en comento, en cuanto hace aplicable a las FFAA el factor de atribución falta de servicio, incurre, a mi juicio, en una patente contradicción con lo previsto expresamente en el artículo 21 inciso $2^{\circ}$ de la LOCBGAE, en tanto dispone que el artículo 42 de la referida ley, que consagra el factor de atribución falta de servicio, no se le aplica a las FFAA, sin que exista norma en sentido contrario en su respectiva ley orgánica constitucional.

\section{Solución que estimo la más acertada al problema planteado}

Estimo que una mejor solución al caso planteado era aplicar el artículo $4^{\circ}$ de la LOCBGAE, propio del estatuto de Derecho Público de la responsabilidad patrimonial de la Administración del Estado, que previene "El Estado será responsable por los daños que causen los órganos de la Administración del Estado en el ejercicio de sus funciones, sin perjuicio de las responsabilidades que pudieran afectar al funcionario que los hubiere ocasionado".

De dicho precepto legal puede inferirse que, para comprometer la responsabilidad del Estado, la víctima debe acreditar al menos una actuación administrativa, daño y relación de causalidad, y como el primero de tales presupuestos se evidencia de dos formas: actuación propiamente tal e inactividad administrativa, y esta última siempre se verifica como la infracción de un deber, bastaba, en la especie, para ese propósito, constatar la infracción de un deber de actuación, en este caso, a mi juicio, de fiscalizar que el arma entregada cumpliera satisfactoriamente las instrucciones internas del Ejército, sin necesidad de forzar la aplicación del factor de atribución falta de servicio en los términos señalados.

\footnotetext{
funciones (sólo ella otorga derecho de reembolso a la Administración sanitaria en su contra); (d) establece un plazo de prescripción de cuatro años contado desde la acción u omisión; (e) precisa que debe entenderse por daño moral la alteración de las condiciones normales de existencia (con lo que, por cierto, lo objetiviza), destacando su carácter compensatorio y no retributivo; (f) exonera a la Administración sanitaria de los dańos consecuentes a los denominados riesgos del desarrollo; $\mathrm{y}$, finalmente, $(\mathrm{g})$ consulta un sistema de mediación previo y obligatorio (cuya constitucionalidad resulta cuestionable en atención a la limitación que impone al derecho a acceso a la justicia). Sobre el particular véase: ROMAN CORDERO, Cristian, HIV+: El deber de notificar al portador (y su infracción como hipótesis de la responsabilidad patrimonial de la Administración sanitaria), Gaceta Jurídica, No 346, p. 14 y ss.
} 
Cabe agregar que la referida inactividad en la especie se hace más evidente en razón de la relevancia del derecho involucrado -la vida de los conscriptos, la necesidad de actuar, y lo exiguos costos que tal actuación importaba en contraste con los beneficios que de ello se seguía ${ }^{15}$ - . Del mismo modo, estimo que la sola circunstancia de haber acontecido el daño en el contexto de un régimen de sujeción especial (conscripción militar), debió haber sido considerado en la especie como presunción de inactividad administrativa (que sería el factor de atribución en la especie), correspondiendo, por tanto, al Fisco, para liberar su responsabilidad, acreditar lo contrario, esto es, que obró con normalidad. 
